\title{
STUDI PENERAPAN KONTRAK LONG SEGMENT UNTUK PRESERYASI JALAN DI KABUPATEN SORONG PAPUA BARAT
}

\author{
Jekson Paulus Iek \\ Magister Teknik Sipil, Program Pascasarjana, Universitas Atma Jaya Yogyakarta \\ Jl. Babarsari No.44, Daerah Istimewa Yogyakarta 55281 \\ Email: $\underline{\text { lennoniek@gmail.com }}$
}

\begin{abstract}
This study aims to determine the readiness of service users, contractors and supervisor consultants on performance indicators in implementing long segment contracts for road preservation in Sorong Regency, and compare whether there are differences in perceptions between service users, contractors and supervisor consultants on these performance indicators in implementing long segment contracts. This study uses statistical analysis methods with the calculation of the mean value, calculation of standard deviation, and Analysis of Variance with the help of Microsoft Exel and SPSS version 20 computer programs in data processing. The results of data processing show that for the level of readiness according to the perception of service users, from the five indicators there are three indicators that are less ready, namely indicators of service provider readiness, payment system indicators and regulatory aspects indicators. For the level of readiness according to the perceptions of the contractor, of the five indicators there are four indicators that are less ready, namely indicators of service provider readiness, monitoring system indicators, payment system indicators and regulatory aspects indicators. And for the level of readiness according to the perceptions of the supervisor consultant, from the five indicators there are three indicators that are less ready, namely indicators of service provider readiness, payment system indicators and regulatory aspects indicators. There is also a perception perception between service users, contractors and supervisor consultants on service user readiness indicators, service provider readiness indicators, supervisory system indicators, payment system indicators and regulatory aspect indicators. Therefore, before implementing a long segment contract for road preservation in Sorong Regency, improvements must be made to indicators that are not ready, so that the standard performance indicators in long segment contracts can be implemented properly.
\end{abstract}

Keywords: Implementation, Long Segment contract, Road preservation

\begin{abstract}
Abstrak
Penelitian ini bertujuan untuk mengetahui kesiapan pengguna jasa, kontraktor dan konsultan pengawas terhadap indikator indikator kinerja dalam penerapan kontrak long segment untuk preservasi jalan di Kabupaten Sorong, dan membandingkan apakah ada perbedaan persepsi antara pengguna jasa, kontraktor dan konsultan pengawas terhadap indikator - indikator kinerja tersebut dalam penerapan kontrak long segment. Penelitian ini menggunakan metode analisis statistik dengan perhitungan nilai mean, perhitungan standar deviasi, dan Analysis of Varians dengan bantuan program komputer Microsoft Exel dan SPSS versi 20 dalam pengolahan data. Hasil pegolahan data diketahui bahwa untuk tingkat kesiapan menurut persepsi pengguna jasa, dari lima indikator yang ada terdapat tiga indikator yang kurang siap yaitu indikator kesiapan penyedia jasa, indikator sistem pembayaran dan indikator aspek regulasi. Untuk tingkat kesiapan menurut persepsi kontraktor, dari lima indikator yang ada terdapat empat indikator yang kurang siap yaitu indikator kesiapan penyedia jasa, indikator sistem pengawasan, indikator sistem pembayaran dan indikator aspek regulasi. Dan untuk tingkat kesiapan menurut persepsi konsultan pengawas, dari lima indikator yang ada terdapat tiga indikator yang kurang siap yaitu indikator kesiapan penyedia jasa, indikator sistem pembayaran dan indikator aspek regulasi. Terdapat juga ada perberdaan persepsi antara pengguna jasa, kontraktor dan konsultan pengawas terhadap indikator kesiapan pengguna jasa, indikator kesiapan penyedia jasa, indikator sistem pengawasan, indikator sistem pembayaran dan indikator aspek regulasi. Oleh karena itu sebelum menerapkan kontrak long segment untuk preservasi jalan di Kabupaten Sorong, maka harus dilakukan pembenahan terhadap indikator - indikator yang kurang siap, sehingga untuk mencapai standar indikator kinerja dalam kontrak long segment bisa diterapkan dengan baik.
\end{abstract}

Kata Kunci: Penerapan, Kontrak Long Segment, Preservasi Jalan

\section{PENDAHULUAN}

(Garner, 2004). Kontrak adalah suatu perjanjian antara dua pihak atau lebih dengan hak dan kewajiban yang dapat diberlakukan atau dikenal dalam hukum atau perundangan yang berlaku, atau dapat juga berupa suatu janji atau serangkaian janji - janji oleh para pihak untuk suatu transaksi yang didasari hukum dan atau perundangan yang berlaku.

(Wirahadikusumah, 2003) dalam (Fauziyah, 2016). Di Indonesia penyelenggaraan infrastruktur jalan umumnya menggunakan jenis kontrak tradisional dengan sistem pembayaran harga satuan (unit price). Namun penggunaan kontrak tradisional dinilai kurang efektif bagi pengguna dan penyedia jasa. Hal ini karena pembayaran prestasi pekerjaan didasarkan atas volume pekerjaan yang dilaksanakan dilapangan seringkali menghasilkan kualitas pekerjaan yang tidak sesuai dengan spesifikasi yang telah ditetapkan.

Kabupaten sorong merupakan salah satu Kabupaten yang terdapat di Provinsi Papua Barat, sebagian besar masyarakat yang berada di Kabupaten Sorong memanfaatkan infrastruktur jalan untuk memudahkan arus mobilisasi baik itu barang atau jasa. Infrastruktur jalan di Kabupaten Sorong sangat membantu dan mempunyai peranan yang sangat penting bagi pertumbuhan ekonomi masyarakat Kabupaten Sorong, karena sebagian besar 
distribusi barang atau jasa dilakukan dengan mengunakan transportasi darat, hanya saja masih terdapat beberapa masalah yang terkait dengan infrastruktur jalan di Kabupaten Sorong yang sering menjadi problem utama bagi masyarakat sorong yaitu terkait dengan penurunan kualitas jalan yang sering rusak atau kurang baik untuk dilalui bagi pengguna jalan yang berada di Kabupaten Sorong.

Berdasarkan (Badan Pusat Statistik 2014). Pajang jalan Kabupaten menurut kondisi di Kabupaten Sorong adalah kondisi jalan baik yaitu $218,31 \mathrm{~km}$, kondisi jalan sedang yaitu $471,53 \mathrm{~km}$, kondisi jalan rusak yaitu $388,36 \mathrm{~km}$ dan kondisi jalan rusak berat yaitu $173,80 \mathrm{~km}$. dan untuk jalan Nasional adalah kondisi jalan baik 70,21 $\mathrm{km}$, kondisi jalan sedang $21,18 \mathrm{~km}$, kondisi jalan rusak $26,63 \mathrm{~km}$ dan kondisi jalan rusak berat $64,17 \mathrm{~km}$.

Untuk mengatasi masalah kerusakan jalan di Kabupaten Sorong, maka Balai Besar Pelaksanaan Jalan Nasional wilayah II sorong setiap tahun mengalokasikan anggaran yang cukup besar dan setiap tahun harus mengadakan lelang proyek untuk memakai jasa para kontraktor (penyedia jasa) untuk mengerjakan proyek kerusakan jalan di Kabupaten Sorong. Balai Besar Pelaksanaan Jalan Nasional wilayah II Sorong selain mengeluarkan anggaran yang cukup besar dan juga masih menggunakan kontrak konvensional. Dimana kontrak Konvensional ini adalah kontrak yang memisahkan proses perencanaan, pelaksanaan, dan pemeliharaan, serta metode cara pembayaran kepada pihak kontraktor yaitu dengan harga satuan (unit price).

(Wijaya, I., Nurmalita, V., Wibowo, M, A., Adi, R, Y., 2014:910). Dalam kontrak konvensional pengguna jasa harus menanggung sepenuhnya risiko-risiko yang berkaitan dengan mutu hasil pekerjaan agar jalan tersebut tetap terpelihara. Problem inilah yang menjadi hambatan utaman bagi Pemerintah Kabupaten Sorong untuk tetap menjaga kualitas jalan di Kabupaten Sorong, tetapi anggaran yang dimiliki sangat terbatas.

Berkaitan dengan masalah tersebut maka dilakukan studi penelitian Penerapan Kontrak Long Segment. Karena dengan jenis kontrak long segment akan lebih efesien dalam pengunaan anggaran jika dibandingkan dengan kontrak konvensional. Karena lingkup pekerjaan dari kontrak long segment untuk preservasi jalan adalah pelebaran, rekonstruksi, rehabilitasi dan pemeliharaan jalan.

(Direktoral Jendral Bina Marga, 2015) dalam (Budilukito, 2016). Melalui Direktorat Preservasi Jalan, akan menerapkan kebijakan long segment untuk preservasi jalan Nasional. Konsep long segment merupakan sistem kontrak yang memungkinkan satu paket kontrak dengan beberapa keluaran penanganan, yaitu pelebaran, rekonstruksi, rehabilitasi, dan pemeliharaan rutin. Panjang ruas jalan yang dikontrakkan sekitar $100 \mathrm{~km}$ dan terdiri atas beberapa ruas jalan.

(Kementerian Pekerjaan Umum, 2011) dalam (Budilukito, 2016). Penerapan long segment ini diharapkan dapat meningkatkan efektivitas penanganan pemeliharaan jalan terutama dari segi anggaran dan dapat meningkatkan kemampuan kontraktor untuk investasi peralatan dan tenaga kerja terampil. Kebijakan long segment diharapkan dapat mengubah paradigma kontraktor yang selama ini hanya sebagai pelaksana kegiatan konstruksi menjadi manajer ruas jalan.

Kebijakan Kontrak Long Segment sejalan dengan Peraturan Menteri Pekerjaan Umum dan Perumahan Rakyat Nomor 13.1/PRT/M/2015 tentang Rencana Strategis Kementerian Pekerjaan Umum dan Perumahan Rakyat Tahun 2015-2019 bahwa, Target Total Panjang jalan Nasional Non Tol yaitu 47. 017 Km (kilo meter) Menuju 98\% Jalan Mantap di Tahun 2019.

Oleh karena itu sebelum menerapkan kontrak long segment untuk preservasi jalan pada proyek - proyek jalan di Kabupaten Sorong, maka akan dilakukan penelitian terlebih dahulu dan tujuan dari penelitian ini adalah Mengidentifikasi Kesiapan Pengguna Jasa, Kontraktor, dan Konsultan Pengawas terhadap indikator kinerja dari kontrak long segment untuk preservasi jalan pada proyek jalan di Kabupaten Sorong dan Mengkaji apakah ada perbedaan persepsi pada indikator Kinerja pada penerapan kontrak long segment untuk preservasi jalan di Kabupaten Sorong menurut pihak pengguna jasa, Kontraktor dan konsultan pengawas.

\section{METODE PENELITIAN}

Dalam penelitian ini metode pengumpulan data dilakukan dengan pengambilan data sekunder dan data primer. Data primer diperoleh dengan cara menyebarkan kuesioner yang bersifat tertutup kepada para responden sebagai subjek penelitian. Jumlah responden yang ditargetkan dalam penyebaran kuesioner yaitu sebanyak 50 (lima puluh) responden, yang diantaranya yaitu sebanyak 20 responden dari pihak Pengguna jasa (Balai Besar Pelaksanaan Jalan Nasional Wilayah II Sorong), 15 responden dari pihak Kontraktor dan 15 responden dari pihak Konsultan Pengawas. Kuesioner dibagi kepada para responden dan diisi dengan dibimbing langsung oleh peneliti. Untuk gambaran penyusunan instrument penelitian dapat dilihat pada tabel 1 dibawah ini.

\begin{tabular}{cc} 
Tabel 1. Instrument Penelitian \\
\hline Variabel & Indikator \\
\hline & $\begin{array}{c}\text { Kesiapan Pengguna Jasa (Satker } \\
\text { PJN wilayah II Sorong) }\end{array}$ \\
\cline { 2 - 2 } Kesiapan Penerapan & Kesiapan Penyedia Jasa \\
Kontrak Long Segment & (Kontraktor) \\
\cline { 2 - 2 } untuk Preservasi Jalan & Indikator Sistem Pengawasan \\
\cline { 2 - 2 } & Indikator Sistem Pembayaran \\
\cline { 2 - 2 } & Indikator Aspek Regulasi \\
\hline
\end{tabular}

Skala pengukuran yang digunakan pada kuesioner ini adalah skala likert untuk mengetahui seberapa besar tingkat kesiapan Pengguna jasa, Kontraktor dan Konsultan Pengawas pada indikator - indikator kinerja dalam penerapan kontrak long segment. Dimana rincian dari skala likert adalah sangat tidak siap nilai skala likert (1), tidak siap nilai skala likert (2), kurang siap nilai skala likert (3), siap nilai skala likert (4) dan sangat siap nilai skala likert (5).

Setalah data primer diperoleh, maka akan dilakukan analisa dengan mengunakan metode statistik yang akan dibantu dengan alat program komputer 
Microsoft Exel dan Statistical Package for the Social Sciences (SPSS) versi 20. Tahapan dalam proses analisa statistik yaitu hitung nilai mean, hitung nilai mean digunakan untuk mengetahui indikator manakah yang sudah siap dalam penerapan kontrak long segment berdasarkan hasil nilai rata - rata pengisian kuesioner dari pihak pengguna jasa, kontraktor dan konsultan pengawas. Rumus mean adalah $\bar{X}$ (rata - rata), n (jumlah responden), $\mathrm{X} i$ (jumlah nilai yang diberikan responden)

$$
\bar{X}=\frac{\sum_{i=n}^{i=n} x i}{n}
$$

Dalam pengukuran nilai mean cenderung menghasilkan nilai yang sama, akan tetapi sebenarnya mempunyai simpangan yang berbeda. Pengukuran penyimpangan merupakan suatu ukuran yang menunjukan tinggi rendahnya perbedaan data yang diperoleh nilai rata - ratanya, oleh karena itu perlu perlu untuk dilakukannya perhitungan standar deviasi. Maka rumus standar deviasi adalah $S D$ (standar deviasi), $\mathrm{X} i$ (jumlah nilai yang diberikan responden ke-), $\bar{X}$ (nilai rata - rata faktor), $n$ ( jumlah responden).

$$
S D=\sqrt{\frac{1}{n-1} \sum_{i=1}^{n}(X i-\bar{X})^{2}}
$$

Setelah mengetahui hasil nilai rata - rata pada setiap indikator pertanyaan yang termuat dalam kuesioner, maka proses analisis selanjutnya yaitu dengan metode analysis of varians (Anova), Analysis of varian adalah salah satu uji komparatif yang digunakan untuk menguji perbedaan mean (rata - rata) data lebih dari dua kelompok. Uji ini digunakan untuk mengetahui ada atau tidaknya perbedaan persepsi terhadap indikator - indikator kinerja dalam penerapan kontrak long segment menurut pihak pengguna jasa, penyedia jasa dan konsultan pengawas.

Interprestasi Hasil akhir dari analisis Anova dengan mengunakan taraf signifikan $(\alpha)$ yang digunakan adalah 0,05 kriteria pengujian sebagai berikut :

a. Jika nilai signifikansi $<a$, maka $\mathrm{H} 1$ diterima (ada perbedaan persepsi pada semua kelompok)

b. Jika nilai signifikansi $>a$, maka H0 diterima (tidak ada perbedaan persepsi pada semua kelompok)

\section{HASIL DAN PEMBAHASAN}

1. Hasil Analisis Mean Kesiapan Pengguna Jasa, Kontraktor dan Konsultan Pengawas dalam Penerapan Kontrak Long Segment.

Pada bagian ini akan menjelaskan secara terperinci tentang indikator - indikator yang mempresentasikan kesiapan pengguna jasa, kontraktor dan konsultan pengawas dalam penerapan kontrak long segment untuk preservasi jalan di Kabupaten Sorong. Untuk itu maka akan dilakukan perhitungan nilai mean pada masing - masing indikator yang ada, sehingga dapat diketahui tingkat kesiapan dalam penerapan kontrak long segment berdasarkan tiga persepsi yang berbeda. Dalam perhitungan nilai mean akan dilakukan secara terperinci bendasarkan ketiga persepsi responden yaitu responden dari pihak pengguna jasa, responden dari pihak kontraktor dan responden dari pihak konsultan pengawas.

a. Kesiapan Pengguna Jasa

Tabel 2. Hasil Rekapitulasi Mean terhadap Kesiapan Pengguna Jasa

\begin{tabular}{lcc}
\hline \multicolumn{1}{c}{ Indikator } & Mean & Standar Deviasi \\
\hline Kesiapan Pengguna Jasa & 4,32 & 0,02 \\
\hline Kesiapan Penyedia Jasa & 3,89 & 0,24 \\
\hline Sistem Pengawasan & 4,06 & 0,01 \\
\hline Sistem Pembayaran & 3,93 & 0,13 \\
\hline Aspek Regulasi & 3,82 & 0,32 \\
\hline
\end{tabular}

Sumber : Hasil Pengolahan data (2019)

Dari hasil perhitungan nilai mean yang terdapat pada tabel dua diatas menunjukan bahwa dari lima indikator, terdapat ada tiga indikator yang kurang siap dalam penerapan kontrak long segment berdasarkan tingkat kesiapan pengguna jasa, indikator - indikator tersebut yaitu indikator kesiapan penyedia jasa, indikator sistem pembayaran dan indikator aspek regulasi. Sedangkan indikator kesiapan pengguna jasa dan indikator sistem pengawasan sudah siap dalam penerapan kontrak long segment.

b. Kesiapan Kontraktor

Tabel 3. Hasil Rekapitulasi Mean terhadap Kesiapan Kontraktor

\begin{tabular}{lcc}
\hline \multicolumn{1}{c}{ Indikator } & Mean & Standar Deviasi \\
\hline Kesiapan Pengguna Jasa & 4,01 & 0,06 \\
\hline Kesiapan Penyedia Jasa & 3,15 & 0,10 \\
\hline Sistem Pengawasan & 3,35 & 0,17 \\
\hline Sistem Pembayaran & 3,36 & 0,12 \\
\hline Aspek Regulasi & 3,13 & 0,04
\end{tabular}

Sumber : Hasil Pengolahan data (2019)

Dari hasil perhitungan nilai mean yang terdapat pada tabel tiga diatas menunjukan bahwa dari lima indikator, terdapat ada empat indikator yang kurang siap dalam penerapan kontrak long segment berdasarkan tingkat kesiapan kontraktor, indikator - indikator tersebut yaitu indikator kesiapan penyedia jasa, indikator sistem pengawasan, indikator sistem pembayaran dan indikator aspek regulasi. Sedangkan indikator kesiapan pengguna jasa sudah siap dalam penerapan kontrak long segment.

c. Kesiapan Konsultan Pengawas

Tabel 4. Hasil Rekapitulasi Mean terhadap Kesiapan Konsultan Pengawas

\begin{tabular}{lcc}
\hline \multicolumn{1}{c}{ Indikator } & Mean & Standar Deviasi \\
\hline Kesiapan Pengguna Jasa & 4,09 & 0,08 \\
\hline Kesiapan Penyedia Jasa & 3,11 & 0,06 \\
\hline Sistem Pengawasan & 4,02 & 0,12 \\
\hline Sistem Pembayaran & 3,69 & 0,03 \\
\hline Aspek Regulasi & 2,86 & 0,08 \\
\hline
\end{tabular}

Sumber : Hasil Pengolahan data (2019) 
Dari hasil perhitungan nilai mean yang terdapat pada tabel empat menunjukan bahwa dari lima indikator, terdapat ada satu indikator yang tidak siap dan dua indikator yang kurang siap dalam penerapan kontrak long segment berdasarkan tingkat kesiapan konsultan pengawas, indikator - indikator tersebut yaitu indikator aspek regulasi, indikator sistem sistem pembayaran dan indikator kesiapan penyedia jasa. Sedangkan indikator kesiapan pengguna jasa dan indikator sistem pengawasan sudah siap dalam penerapan kontrak long segment.

2. Hasil Analisi Anova tentang apakah ada perbedaan persepsi terhadap semua indikator penelitian antara pihak Pengguna Jasa, Kontraktor dan Konsultan Pengawas dalam penerapan kontrak long segment.

Pada bagian ini akan menjelaskan secara terperinci tentang apakah ada perbedaan persepsi terhadap indikator - indikator dalam penerapan kontrak long segment menurut pihak pengguna jasa, kontraktor dan konsultan pengawas.

a. Hasil Pengujian Anova

Tabel 5. Hasil Uji Anova terhadap Indikator Kesiapan Pengguna jasa

\begin{tabular}{cccccc}
\hline & $\begin{array}{c}\text { Sum of } \\
\text { Squares }\end{array}$ & df & $\begin{array}{c}\text { Mean } \\
\text { Square }\end{array}$ & F & Sig. \\
\hline Between Groups & 3056.095 & 2 & 1528.048 & 148.790 & .000 \\
Within Groups & 184.857 & 18 & 10.270 & & \\
Total & 3240.952 & 20 & & & \\
\hline
\end{tabular}

Sumber : Hasil Pengolahan data (2019)

Berdasarkan hasil uji anova pada tabel lima diatas menunjukan bahwa, pada indikator kesiapan pengguna jasa terdapat ada perbedaan persepsi antara pengguna jasa, kontraktor dan konsultan pengawas dalam penerapan kontrak long segment. Dikarenakan nilai signifikansi $(.000)<a(0,05)$, maka H1 diterima (ada perbedaan persepsi pada semua kelompok).

Tabel 6. Hasil Uji Post Hoc Indikator Kesiapan Pengguna jasa

\begin{tabular}{|c|c|c|c|c|c|c|}
\hline \multirow[b]{2}{*}{$\begin{array}{c}\text { (I) } \\
\text { Responden }\end{array}$} & \multirow[b]{2}{*}{$\begin{array}{c}(\mathbf{J}) \\
\text { Responden }\end{array}$} & \multirow[b]{2}{*}{$\begin{array}{c}\text { Mean } \\
\text { Difference } \\
(\mathbf{I}-\mathrm{J})\end{array}$} & \multirow[b]{2}{*}{$\begin{array}{l}\text { Std. } \\
\text { Error }\end{array}$} & \multirow[b]{2}{*}{ Sig. } & \multicolumn{2}{|c|}{ 95\% Confidence Interval } \\
\hline & & & & & $\begin{array}{l}\text { Lower } \\
\text { Bound }\end{array}$ & $\begin{array}{l}\text { Upper } \\
\text { Bound }\end{array}$ \\
\hline \multirow{2}{*}{$\begin{array}{c}\text { Pengguna } \\
\text { Jasa }\end{array}$} & Kontraktor & $26.14286^{*}$ & 1.71296 & .000 & 22.5441 & 29.7417 \\
\hline & Konsultan & $25.00000^{*}$ & 1.71296 & .000 & 21.4012 & 28.5988 \\
\hline \multirow{2}{*}{ Kontraktor } & Pengguna Jasa & $-26.14286^{*}$ & 1.71296 & .000 & -29.7417 & -22.5441 \\
\hline & Konsultan & -1.14286 & 1.71296 & .513 & -4.7417 & 2.4559 \\
\hline \multirow{2}{*}{ Konsultan } & Pengguna Jasa & $-25.00000^{*}$ & 1.71296 & .000 & -28.5988 & -21.4012 \\
\hline & Kontraktor & 1.14286 & 1.71296 & .513 & -2.4559 & 4.7417 \\
\hline
\end{tabular}

Sumber : Hasil Pengolahan data (2019)

Berdasarkan hasil pengujian post hoc pada tabel enam diatas menunjukan bahwa, antara pihak pengguna jasa, pihak kontraktor dan konsultan pengawas terdapat ada perbedaan persepsi oleh karena nilai sig (.000) $<a$ $(0,05)$, maka keputusanya H1 diterima. Sedangkan antara pihak kontraktor dan pihak konsultan pengawas tidak terdapat perbedaan persepsi oleh karena nilai sig (.513) $>a$ $(0,05)$, maka keputusanya H0 diterima.
Tabel 7. Hasil Uji Anova terhadap Indikator Kesiapan

Penyedia jasa

\begin{tabular}{cccccc}
\hline & $\begin{array}{c}\text { Sum of } \\
\text { Squares }\end{array}$ & df & $\begin{array}{c}\text { Mean } \\
\text { Square }\end{array}$ & F & Sig. \\
\hline Between Groups & 5705.556 & 2 & 2852.778 & 89.330 & .000 \\
Within Groups & 766.444 & 24 & 31.935 & & \\
Total & 6472.000 & 26 & & & \\
\hline
\end{tabular}

Sumber : Hasil Pengolahan data (2019)

Berdasarkan hasil uji anova pada tabel tujuh diatas menunjukan bahwa, pada indikator kesiapan penyedia jasa terdapat ada perbedaan persepsi antara pengguna jasa, kontraktor dan konsultan pengawas dalam penerapan kontrak long segment. Dikarenakan nilai signifikansi $(.000)<a(0,05)$, maka H1 diterima (ada perbedaan persepsi pada semua kelompok).

Tabel 8. Hasil Uji Post Hoc Indikator Kesiapan Penyedia jasa

\begin{tabular}{|c|c|c|c|c|c|c|}
\hline \multirow{2}{*}{$\begin{array}{c}\text { (I) } \\
\text { Responden }\end{array}$} & \multirow{2}{*}{$\begin{array}{c}(\mathbf{J}) \\
\text { Responden }\end{array}$} & \multirow{2}{*}{$\begin{array}{c}\text { Mean } \\
\text { Difference } \\
\text { (I-J) }\end{array}$} & \multirow{2}{*}{$\begin{array}{l}\text { Std. } \\
\text { Error }\end{array}$} & \multirow[t]{2}{*}{ Sig. } & \multicolumn{2}{|c|}{$\begin{array}{l}\text { 95\% Confidence } \\
\text { Interval }\end{array}$} \\
\hline & & & & & $\begin{array}{l}\text { Lower } \\
\text { Bound }\end{array}$ & $\begin{array}{l}\text { Upper } \\
\text { Bound }\end{array}$ \\
\hline Pengguna & Kontraktor & $30.55556^{*}$ & 2.66396 & .000 & 25.0574 & 36.0537 \\
\hline Jasa & Konsultan & $31.11111^{*}$ & 2.66396 & .000 & 25.6130 & 36.6093 \\
\hline Kontraktor & Pengguna Jasa & $\begin{array}{c}30.55556^{*} \\
.55556\end{array}$ & $\begin{array}{l}2.06390 \\
2.66396\end{array}$ & $\begin{array}{l}.000 \\
.837\end{array}$ & $\begin{array}{l}36.0537 \\
-4.9426\end{array}$ & $\begin{array}{c}-25.0574 \\
6.0537\end{array}$ \\
\hline Konsultan & Pengguna Jasa & $-31.11111^{*}$ & 2.66396 & .000 & -36.6093 & -25.6130 \\
\hline & Kontraktor & & & & & \\
\hline
\end{tabular}

Sumber : Hasil Pengolahan data (2019)

Berdasarkan hasil pengujian post hoc pada tabel delapan diatas menunjukan bahwa, antara pihak pengguna jasa, pihak kontraktor dan konsultan pengawas terdapat ada perbedaan persepsi oleh karena nilai sig (.000) < $a$ $(0,05)$, maka keputusanya $\mathrm{H} 1$ diterima. Sedangkan antara pihak kontraktor dan pihak konsultan pengawas tidak terdapat perbedaan persepsi oleh karena nilai sig $(.837)>a$ $(0,05)$, maka keputusanya H0 diterima.

Tabel 9. Hasil Uji Anova terhadap Indikator Sistem Pengawasan

\begin{tabular}{cccccc}
\hline & $\begin{array}{c}\text { Sum of } \\
\text { Squares }\end{array}$ & df & $\begin{array}{c}\text { Mean } \\
\text { Square }\end{array}$ & F & Sig. \\
\hline Between Groups & 1302.000 & 2 & 651.000 & 42.457 & .000 \\
Within Groups & 92.000 & 6 & 10.270 & & \\
Total & 1394.000 & 8 & & & \\
\hline
\end{tabular}

Sumber : Hasil Pengolahan data (2019)

Berdasarkan hasil uji anova pada tabel sembilan diatas menunjukan bahwa, pada indikator sistem pengawasan terdapat ada perbedaan persepsi antara pengguna jasa, kontraktor dan konsultan pengawas dalam penerapan kontrak long segment. Dikarenakan nilai signifikansi $(.000)<a(0,05)$, maka H1 diterima (ada perbedaan persepsi pada semua kelompok).

Berdasarkan hasil pengujian post hoc pada tabel 10 di bawah menunjukan bahwa, antara pihak pengguna jasa, pihak kontraktor dan konsultan pengawas terdapat ada perbedaan persepsi oleh karena nilai sig (.000, .001, $.020)<a(0,05)$, maka keputusanya H1 diterima. 
Tabel 10. Hasil Uji Post Hoc Indikator Sistem Pengawasan

\begin{tabular}{|c|c|c|c|c|c|c|}
\hline \multirow[b]{2}{*}{$\begin{array}{c}\text { (I) } \\
\text { Responden }\end{array}$} & \multirow[b]{2}{*}{$\begin{array}{c}(\mathbf{J}) \\
\text { Responden }\end{array}$} & \multirow[b]{2}{*}{$\begin{array}{c}\text { Mean } \\
\text { Difference } \\
\text { (I-J) }\end{array}$} & \multirow[b]{2}{*}{$\begin{array}{l}\text { Std. } \\
\text { Error }\end{array}$} & \multirow[b]{2}{*}{ Sig. } & \multicolumn{2}{|c|}{ 95\% Confidence Interva } \\
\hline & & & & & $\begin{array}{l}\text { Lower } \\
\text { Bound }\end{array}$ & $\begin{array}{l}\text { Upper } \\
\text { Bound }\end{array}$ \\
\hline \multirow{2}{*}{$\begin{array}{c}\text { Pengguna } \\
\text { Jasa }\end{array}$} & Kontraktor & $29.00000^{*}$ & 3.19722 & .000 & 21.1767 & 36.8233 \\
\hline & Konsultan & $19.00000^{*}$ & 3.19722 & .001 & 11.1767 & 26.8233 \\
\hline \multirow{2}{*}{ Kontraktor } & Pengguna Jasa & $29.00000^{*}$ & 3.19722 & .000 & -36.8233 & -21.1767 \\
\hline & Konsultan & $19.00000^{*}$ & 3.19722 & .020 & -17.8233 & -2.1767 \\
\hline \multirow[b]{2}{*}{ Konsultan } & Pengguna Jasa & \multirow{2}{*}{$\begin{array}{l}29.00000^{*} \\
19.00000^{*}\end{array}$} & \multirow{2}{*}{$\begin{array}{l}3.19722 \\
3.19722\end{array}$} & \multirow{2}{*}{$\begin{array}{l}.001 \\
.020\end{array}$} & \multirow{2}{*}{$\begin{array}{c}-26.8233 \\
2.1767\end{array}$} & \multirow{2}{*}{$\begin{array}{r}-11.1767 \\
17.8233\end{array}$} \\
\hline & Kont & & & & & \\
\hline
\end{tabular}

Sumber : Hasil Pengolahan data (2019)

Tabel 11. Hasil Uji Anova terhadap Indikator Sistem Pembayaran

\begin{tabular}{cccccc}
\hline & $\begin{array}{c}\text { Sum of } \\
\text { Squares }\end{array}$ & df & $\begin{array}{c}\text { Mean } \\
\text { Square }\end{array}$ & F & Sig. \\
\hline Between Groups & 2302.381 & 2 & 1151.190 & 27.894 & .000 \\
Within Groups & 742.857 & 18 & 41.270 & & \\
Total & 3045.238 & 20 & & & \\
\hline
\end{tabular}

Sumber : Hasil Pengolahan data (2019)

Berdasarkan hasil uji anova pada tabel 11 diatas menunjukan bahwa, pada indikator sistem pembayaran terdapat ada perbedaan persepsi antara pengguna jasa, kontraktor dan konsultan pengawas dalam penerapan kontrak long segment. Dikarenakan nilai signifikansi $(.000)<a(0,05)$, maka H1 diterima (ada perbedaan persepsi pada semua kelompok).

Tabel 12. Hasil Uji Post Hoc Indikator Sistem Pembayaran

\begin{tabular}{|c|c|c|c|c|c|c|}
\hline \multirow[b]{2}{*}{$\begin{array}{c}\text { (I) } \\
\text { Responden }\end{array}$} & \multirow[b]{2}{*}{$\begin{array}{c}(\mathbf{J}) \\
\text { Responden }\end{array}$} & \multirow[b]{2}{*}{$\begin{array}{c}\text { Mean } \\
\text { Difference } \\
\text { (I-J) }\end{array}$} & \multirow[b]{2}{*}{$\begin{array}{l}\text { Std. } \\
\text { Error }\end{array}$} & \multirow[b]{2}{*}{ Sig. } & \multicolumn{2}{|c|}{ 95\% Confidence Interval } \\
\hline & & & & & $\begin{array}{l}\text { Lower } \\
\text { Bound }\end{array}$ & $\begin{array}{l}\text { Upper } \\
\text { Bound }\end{array}$ \\
\hline \multirow{2}{*}{$\begin{array}{c}\text { Pengguna } \\
\text { Jasa }\end{array}$} & Kontraktor & $24.28571^{*}$ & 3.43386 & .000 & 17.0714 & 31.5000 \\
\hline & Konsultan & $19.28571^{*}$ & 3.43386 & .000 & 12.0714 & 26.5000 \\
\hline \multirow{2}{*}{ Kontraktor } & Pengguna Jasa & $-24.28571^{*}$ & 3.43386 & .000 & -31.5000 & -17.0714 \\
\hline & Konsultan & -5.00000 & 3.43386 & .163 & -12.2143 & 2.2143 \\
\hline \multirow{2}{*}{ Konsultan } & Pengguna Jasa & $-19.28571^{*}$ & 3.43386 & .000 & -26.5000 & -12.0714 \\
\hline & Kontraktor & 5.00000 & 3.43386 & .163 & -2.2143 & 12.2143 \\
\hline
\end{tabular}

Sumber : Hasil Pengolahan data (2019)

Berdasarkan hasil pengujian post hoc pada tabel 12 diatas menunjukan bahwa, antara pihak pengguna jasa, pihak kontraktor dan konsultan pengawas terdapat ada perbedaan persepsi oleh karena nilai sig $(.000)<a(0,05)$, maka keputusanya H1 diterima. Sedangkan antara pihak kontraktor dan pihak konsultan pengawas tidak terdapat perbedaan persepsi oleh karena nilai sig $(.163)>a(0,05)$, maka keputusanya $\mathrm{H} 0$ diterima.

Tabel 13. Hasil Uji Anova terhadap Indikator Aspek Regulasi

\begin{tabular}{cccccc}
\hline & $\begin{array}{c}\text { Sum of } \\
\text { Squares }\end{array}$ & df & $\begin{array}{c}\text { Mean } \\
\text { Square }\end{array}$ & F & Sig. \\
\hline Between Groups & 1045.333 & 2 & 522.667 & 9.709 & .049 \\
Within Groups & 161.500 & 3 & 53.833 & & \\
Total & 1206.833 & 5 & & & \\
\hline
\end{tabular}

Sumber : Hasil Pengolahan data (2019)

Berdasarkan hasil uji anova pada tabel 13 di atas menunjukan bahwa, pada indikator aspek regulasi terdapat ada perbedaan persepsi antara pengguna jasa, kontraktor dan konsultan pengawas dalam penerapan kontrak long segment. Dikarenakan nilai signifikansi $(.049)<a(0,05)$, maka H1 diterima (ada perbedaan persepsi pada semua kelompok).

Tabel 14. Hasil Uji Post Hoc Indikator Aspek Regulasi

\begin{tabular}{|c|c|c|c|c|c|c|}
\hline \multirow[b]{2}{*}{$\begin{array}{c}\text { (I) } \\
\text { Responden }\end{array}$} & \multirow[b]{2}{*}{$\begin{array}{c}(\mathbf{J}) \\
\text { Responden }\end{array}$} & \multirow[b]{2}{*}{$\begin{array}{c}\text { Mean } \\
\text { Difference } \\
(\mathbf{I}-\mathbf{J})\end{array}$} & \multirow[b]{2}{*}{$\begin{array}{l}\text { Std. } \\
\text { Error }\end{array}$} & \multirow[b]{2}{*}{ Sig. } & \multicolumn{2}{|c|}{ 95\% Confidence Interval } \\
\hline & & & & & $\begin{array}{l}\text { Lower } \\
\text { Bound }\end{array}$ & $\begin{array}{l}\text { Upper } \\
\text { Bound }\end{array}$ \\
\hline \multirow{2}{*}{$\begin{array}{c}\text { Pengguna } \\
\text { Jasa }\end{array}$} & Kontraktor & $28.00000^{*}$ & 7.33712 & .032 & 4.6500 & 51.3500 \\
\hline & Konsultan & $28.00000^{*}$ & 7.33712 & .032 & 4.6500 & 51.3500 \\
\hline \multirow{2}{*}{ Kontraktor } & Pengguna Jasa & $-28.00000^{*}$ & 7.33712 & .032 & -51.3500 & -4.6500 \\
\hline & Konsultan & .00000 & 7.33712 & 1.000 & -23.3500 & 23.3500 \\
\hline \multirow{2}{*}{ Konsultan } & Pengguna Jasa & $-28.00000^{*}$ & 7.33712 & .032 & -51.3500 & -4.6500 \\
\hline & Kontraktor & .00000 & 7.33712 & 1.000 & -23.3500 & 23.3500 \\
\hline
\end{tabular}

Berdasarkan hasil pengujian post hoc pada tabel 14 menunjukan bahwa, antara pihak pengguna jasa, pihak kontraktor dan konsultan pengawas terdapat ada perbedaan persepsi oleh karena nilai sig $(.032)<a(0,05)$, maka keputusanya H1 diterima. Sedangkan antara pihak kontraktor dan pihak konsultan pengawas tidak terdapat perbedaan persepsi oleh karena nilai sig $(1.000)>a(0,05)$, maka keputusanya $\mathrm{H} 0$ diterima.

b. Rekapitulasi Hasil Pengujian Anova Berdasarkan Persepsi Pengguna Jasa, Kontraktor dan Konsultan Pengawas dalam Penerapan Kontrak Long Segment

Tabel 15. Rekapitulasi Uji Anova terhadap Indikator Kinerja dalam Penerapan Long Segment

\begin{tabular}{lccc}
\hline \multicolumn{1}{c}{ Indikator } & $\begin{array}{c}\text { Pengguna } \\
\text { jasa dan } \\
\text { Kontraktor }\end{array}$ & $\begin{array}{c}\text { Pengguna } \\
\text { jasa dan } \\
\text { Konsultan }\end{array}$ & $\begin{array}{c}\text { Kontraktor } \\
\text { dan konsultan }\end{array}$ \\
\hline $\begin{array}{l}\text { Kesiapan } \\
\text { Pengguna Jasa }\end{array}$ & Beda & Beda & Tidak beda \\
\hline $\begin{array}{l}\text { Kesiapan } \\
\text { Penyedia Jasa }\end{array}$ & Beda & Beda & Tidak beda \\
\hline $\begin{array}{l}\text { Indikator Sistem } \\
\text { Pengawasan }\end{array}$ & Beda & Beda & Beda \\
\hline $\begin{array}{l}\text { Indikator Sistem } \\
\text { Pembayaran }\end{array}$ & Beda & Beda & Tidak beda \\
\hline $\begin{array}{l}\text { Indikator Aspek } \\
\text { Regulasi }\end{array}$ & Beda & Beda & Tidak beda \\
\hline
\end{tabular}

Pada Indikator Kesiapan Pengguna Jasa Perbedaan Perbedaan tersebut dikarenakan pihak pengguna jasa menitikberatkan pada indikator Pengguna jasa setiap saat melakukan inspeksi lapangan untuk memantau kinerja kontraktor. Untuk pihak kontraktor menitikberatkan pada indikator Menetapkan ruas jalan yang masuk dalam skema kontrak long segment. Sedangkan untuk pihak konsultan pengawas menitikberatkan pada indikator Pembentukan panitia lelang yang memiliki kapabilitas dalam penerapan sistem long segment.

Pada Indikator Kesiapan Penyedia Jasa Perbedaan tersebut dikarenakan pihak pengguna jasa menitikberatkan terhadap indikator Penyedia jasa menggunakan tenaga kerja ahli yang mampu menerima konsep long segment, Penyedia jasa melakukan investasi personil dengan kualitas baik untuk mencapai hasil kinerja yang maksimal. Untuk pihak kontraktor menitikberatkan pada indikator Penyedia jasa harus membuat laporan 
mingguan dalam pemenuhan tingkat layanan jalan dan laporan bulanan untuk tingkat layanan jembatan, Memiliki metode dan alat yang akan digunakan selama dalam pelaksanaan pekerjaan. Sedangkan untuk pihak konsultan pengawas menitikberatka terhadap indikator Penyedia jasa selalu berusah untuk mencapai standar kinerja jalan yang telah disepakati, Penyedia Jasa harus memenuhi semua indikator kinerja jalan dan jembatan.

Pada Indikator Sistem Pengawasan Perbedaan tersebut dikarenakan pihak pengguna jasa menitikberakan pada indikator Pengawasan dari direksi teknis (pihak proyek) dilakukan rutin atau setiap hari. Untuk pihak kontraktor menitikberatkan pada indikator Pejabat Pembuat Komitmen (PPK) sudah siap di dalam melakukan inspeksi lapangan setiap saat. Sedangkan untuk pihak konsultan pengawas menitikberatkan pada Adanya sanksi atas tidak terpenuhinya indikator kinerja jalan dan jembatan yang ada dalam kontrak.

Pada Indikator Sistem Pembayaran Perbedaan tersebut dikarenakan pihak pengguna jasa menitikberatkan terhadap indikator Apabila total nilai pemotongan pembayaran akibat keterlambatan pemenuhan tingkat layanan jalan dan jembatan lebih besar 5\% dari nilai lingkup pekerjaan pemeliharaan jalan dan jembatan, maka kontrak dinyatakan kritis, Apabila pelaksanaan lingkup pekerjaan pemeliharaan rutin jalan dan pemeliharaan rutin jembatan tidak atau belum dilaksanakan sesuai dengan jadwal pelaksanaan pekerjaan yang telah disetujui oleh PPK maka pembayaran prestasi seluruh lingkup pekerjaan akan ditunda sampai dengan pelaksanaan pemeliharaan rutin jalan dan jembatan telah dilaksanakan sesuai jadwal pelaksanaan dan hasilnya memenuhi tingkat layanan jalan dan jembatan. Untuk pihak kontraktor menitikberatkan pada indikator Jika PPK atau Direksi teknis menemuka suatu bagian jalan atau jembatan yang tidak memenuhi kriteria tingkat layanan maka hasil inspeksi akan di sampaikan kepada penyedia jasa dan jika penyedia jasa tidak dapat menindak lanjuti untuk melakukan perbaikan maka akan dikenakan sanksi pemotongan pembayaran. Sedangkan untuk pihak konsultan pengawas menitikberatkan pada indikator Pembayaran prestasi pekerjaan dilakukan dengan cara bulanan, Pembayaran sertifikat bulanan (monthly certificate) selanjutnya dapat dilakukan apabila penyedia jasa telah memenuhi kewajiban pembayaran akibat keterlambatan pemenuhan tingkat layanan jalan dan jembatan.

Pada Indikator Aspek Regulasi Perbedaan tersebut dikarenakan pihak pengguna jasa menitikberatkan terhadap indikator Adanya peraturan yang mengatur prosedur kontrak long segment. Sedangkan kontraktor dan konsultan menitikberatkan pada indikator Adanya penyesuaian masa kontrak menjadi kontrak tahun jamak.

\section{KESIMPULAN}

Berdasarkan hasil analisis dan pembahasan maka dapat disimpulkan bahwa:

1. Tentang tingkat kesiapan terhadap indikator - indikator kinerja dalam penerapan kontrak long segment berdasarkan kesiapan pengguna jasa, kontraktor dan konsultan pengawas : a. Pada indikator kesiapan pengguna jasa, dari lima indikator terdapat ada dua indikator yang sudah mengambarkan kesiapan dalam penerapan kontrak long segment yaitu indikator kesiapan pengguna jasa dan indikator sistem pengawasan. Sedangkan untuk indikator kesiapan penyedia jasa, indikator sistem pembayaran dan indikator aspek regulasi kurang siap dalam penerapan kontrak long segment.

b. Pada indikator kesiapan kontraktor, dari lima indikator terdapat ada satu indikator yang mengambarkan kesiapan dalam penerapan kontrak long segment yaitu indikator kesiapan pengguna jasa. Sedangkan untuk indikator kesiapan penyedia jasa, indikator sistem pengawasan, indikator sistem pembayaran dan indikator aspek regulasi kurang siap dalam penerapan kontrak long segment.

c. Pada indikator kesiapan konsultan pengawas, dari lima indikator terdapat ada dua indikator yang mengambarkan kesiapan dalam penerapan kontrak long segment yaitu indikator kesiapan pengguna jasa dan indikator sistem pengawasan. Sedangkan untuk indikator kesiapan penyedia jasa, indikator sistem pembayaran dan indikator aspek regulasi kurang siap dalam penerapan kontrak long segment.

2. Tentang uji Anova untuk membandingkan apakah ada persepsi terhadapat indikator - indikator kinerja antara pihak pengguna jasa, kontraktor dan konsultan pengawas dalam penerapan kontrak long segment:

a. Pada indikator kesiapan pengguna jasa terdapat ada perbedaan persepsi antara pengguna jasa, kontraktor dan konsultan pengawasa oleh karena nilai signifikansi $(.000)<a(0,05)$. Sedangkan antara kontraktor dan konsultan pengawas tidak terdapat perbedaan persepsi oleh karena nilai signifikansi $(.513)>a(0,05)$.

b. Pada indikator kesiapan penyedia jasa terdapat ada perbedaan persepsi antara pengguna jasa, kontraktor dan konsultan pengawasa oleh karena nilai signifikansi $(.000)<a(0,05)$. Sedangkan antara kontraktor dan konsultan pengawas tidak terdapat perbedaan persepsi oleh karena nilai signifikansi $(.837)>a(0,05)$.

c. Pada indikator sistem pengawasan terdapat ada perbedaan persepsi antara pengguna jasa, kontraktor dan konsultan pengawasa oleh karena nilai signifikansi $(.000, .001, .020)<a(0,05)$. Sedangkan antara kontraktor dan konsultan pengawas juga terdapat ada perbedaan persepsi oleh karena nilai signifikansi $(.020)<a(0,05)$.

d. Pada indikator sistem pembayaran terdapat ada perbedaan persepsi antara pengguna jasa, kontraktor dan konsultan pengawasa oleh karena nilai signifikansi $(.000)<a(0,05)$. Sedangkan antara kontraktor dan konsultan pengawas tidak terdapat perbedaan persepsi oleh karena nilai signifikansi $(.163)>a(0,05)$.

e. Pada indikator aspek regulasi terdapat ada perbedaan persepsi antara pengguna jasa, kontraktor dan konsultan pengawasa oleh karena nilai signifikansi $(.031)<a(0,05)$. Sedangkan antara kontraktor dan 
konsultan pengawas tidak terdapat perbedaan persepsi oleh karena nilai signifikansi (1.000) $>a$ $(0,05)$.

\section{SARAN}

Berdasarkan hasil analisis yang telah dilakukan ditemukan bahwa masih ada indikator - indikator yang belum siap di dalam penerapan kontrak long segment untuk preservasi jalan di Kabupaten Sorong. Oleh karena itu harus dilakukan pembenahan - pembenahan terlebih dahulu sebelum menerapkan kontrak tersebut.

1. Pada tabel 2. Hasil Perhitungan Nilai Mean dan Standar Deviasi untuk indikator kesiapan pengguna jasa ditemukan bahwa indikator kesiapan penyedia jasa, indikator sistem pembayaran dan indikator aspek regulasi adalah kurang siap. Oleh karena itu pemerintah perlu memberikan dorongan dan memberikan leluasan kepada para penyedia jasa yaitu kontraktor dan konsultan pengawas di dalam meningkatkan sumber daya manusia, sumber daya perusahaan dan harus ada suatu regulasi daerah yang mengatur prosedur kontrak long segment.

2. Pada tabel 3. Hasil Perhitungan Nilai Mean dan Standar Deviasi untuk indikator kesiapan kontraktor ditemukan bahwa indikator kesiapan penyedia jasa, indikator sistem pengawasan, indikator sistem pembayaran dan indikator aspek regulasi adalah kurang siap. Oleh karena itu pemerintah daerah harus melakukan inovasi kontrak yang menitikberatkan pada hasil akhir pekerjaan serta indikator kinerja yang harus dicapai oleh penyedia jasa dalam pekerjaan konstruksi, sehingga kemampuan para penyedia jasa yaitu kontraktor dan konsultan pengawas agar selalu dapat meningkatkan sumber daya manusia dan sumber daya manajemen perusahaan agar dapat mencapai standar kinerja yang ada dalam kontrak tersebut.

3. Pada tabel 4. Hasil Perhitungan Nilai Mean dan Standar Deviasi untuk indikator kesiapan konsultan pengawas ditemukan bahwa indikator kesiapan penyedia jasa, indikator sistem pembayaran dan indikator aspek regulasi adalah kurang siap. Oleh karena itu pemerintah daerah perlu melakukan pembenahan - pembenahan terhadap kemampuan kontraktor dalam melakukan investasi tenaga kerja yang terampil dan adanya penyesuaian masa kontrak menjadi kontrak tahun jamak.

4. Pemerintah daerah perlu meningkatkan budaya persaingan usaha yang sehat dalam bidang jasa konsutruksi sehingga tidak terdapat lagi sistem korupsi, kolusi dan nepotisme (KKN). Karena dengan adanya persaingan usaha yang sehat maka setiap penyedia jasa dituntut untuk meningkatkan sumber daya manusia perusahaan, sumber daya manajemen perusahaan dan sumber daya peralatan perusahaan.

\section{DAFTAR PUSTAKA}

Badan Pusat Statistik Kabupaten Sorong, (2014), "Panjang Jalan Kabupaten dan Provinsi Menurut Kondisi di
Kabupaten Sorong", diakses 26 September 2018, https://sorongkab.bps.go.id/subject/17/transportasi.ht ml\#subjekView ab3.

Budilukito, A., (2016), "Kesiapan Kontraktor terhadap Kebijakan Preservasi Jalan Nasional di Sumatera Selatan", Jurnal HPJI, Vol. 2, No. 2.

Fauziyah, S., (2016), "Analisis Perbandingan Kontrak Tradisional dan Kontrak Berbasis Kinerja (KBK) Berdasarkan Risiko Persepsi Kontraktor dengan Metode Analytical Hierarchy Process (AHP)", Jurnal Ilmu dan Terapan Bidang Teknik Sipil, Vol. 22, No. 1 .

Peraturan Menteri Pekerjaan Umum Perumahan Rakyat, (2015), "rencana strategis 2015-2019" Kementerian Pekerjaan Umum dan Perumahan Rakyat, Jakarta.

Sarwono Hardjomuljadi, (2014), Buku Kesatu Pengatar Kontrak Konstruksi (FIDIC CONDITIONS OF CONTRACT), Diterbitkan dengan Kerjasama : Kementerian Pekerjaan Umum Perumahan Rakyat Republik Indonesia, Kementerian Riset Teknologi dan Pendidikan Tinggi Republik Indonesia, Universitas Mercu Buana Jakarta.

Wijaya, I., Nurmalita, V., Wibowo, M, A., Adi, R, Y., (2014), "Analisis Kontrak Berbasis Kinerja dan Kontrak Konvensional (Studi Kasus Proyek Pembangunan Jalan KBK Semarang-Bawen dan Proyek Pembangunan Jalan Tol Semarang-Solo", Jurnal Karya Teknik Sipil, Vol 3, No 4. 


\section{DAFTAR LAMPIRAN}

Lampiran 1. Hasil Analisis Mean terhadap Kesiapan Pengguna jasa menurut pihak pengguna jasa, kontraktor dan konsultan pengawas.

\begin{tabular}{clccc}
\hline No & \multicolumn{1}{c}{$\begin{array}{c}\text { Pertanyaan } \\
\text { Indikator Kesiapan Pengguna Jasa }\end{array}$} & $\begin{array}{c}\text { Mean } \\
\text { Pesiapan } \\
\text { Pengguna Jasa }\end{array}$ & $\begin{array}{c}\text { Kesiapan } \\
\text { Kontraktor }\end{array}$ & $\begin{array}{c}\text { Kesiapan Konsultan } \\
\text { Pengawas }\end{array}$ \\
\hline 1 & $\begin{array}{l}\text { Pembentukan panitia lelang yang memiliki kapabilitas dalam } \\
\text { penerapan sistem long segment. }\end{array}$ & 4,3 & 4,26 \\
\hline 2 & $\begin{array}{l}\text { Meyiapkan dokumen kontrak yang mencantumkan standar } \\
\text { kinerja jalan dan jembatan dalam penerapan long segment }\end{array}$ & 4,3 & 3,93 & 3,93 \\
\hline 3 & $\begin{array}{l}\text { Menetapkan standar ruang lingkup pekerjaan dan indikator } \\
\text { kinerja dalam long segment. }\end{array}$ & 4,25 & 4,33 & 4 \\
\hline & $\begin{array}{l}\text { Penyiapan administrasi prakualifikasi untuk menyeleksi } \\
\text { kontraktor yang memiliki kemampuan teknis dan keuangan } \\
\text { dalam melaksanakan long segment. }\end{array}$ & 4,25 & 4,26 & 3,13 \\
\hline 5 & $\begin{array}{l}\text { Memberikan kepastian anggaran untuk pekerjaan long segment } \\
\text { dalam bentuk kontrak tahun jamak. }\end{array}$ & 4,3 & 3,46 \\
\hline 6 & $\begin{array}{l}\text { Pengguna jasa setiap saat melakukan inspeksi lapangan untuk } \\
\text { memantau kinerja kontraktor. }\end{array}$ & 4,45 & 3,93 \\
\hline 7 & $\begin{array}{l}\text { Menetapkan ruas jalan yang masuk dalam skema kontrak long } \\
\text { segment }\end{array}$ & 4,4 & 4,2 & 4,13 \\
\hline & \multicolumn{1}{c}{ Rata - rata } & $\mathbf{4 , 3 2}$ & $\mathbf{4 , 0 1}$ \\
\hline
\end{tabular}

Lampiran 2. Hasil Analisis Mean terhadap Kesiapan Penyedia jasa menurut pihak pengguna jasa, kontraktor dan konsultan pengawas

\begin{tabular}{|c|c|c|c|c|}
\hline \multirow[b]{2}{*}{ No } & \multirow[b]{2}{*}{$\begin{array}{l}\text { Pertanyaan } \\
\text { Indikator Kesiapan Penyedia Jasa }\end{array}$} & Mean & Mean & Mean \\
\hline & & $\begin{array}{c}\text { Kesiapan } \\
\text { Pengguna Jasa }\end{array}$ & $\begin{array}{l}\text { Kesiapan } \\
\text { Kontraktor }\end{array}$ & $\begin{array}{l}\text { Kesiapan Konsultan } \\
\text { Pengawas }\end{array}$ \\
\hline 1 & $\begin{array}{l}\text { Penyedia jasa menerima resiko selama masa kontrak long } \\
\text { segment. }\end{array}$ & 3,65 & 3,13 & 2,66 \\
\hline 2 & $\begin{array}{l}\text { Memiliki metode dan alat yang akan digunakan selama dalam } \\
\text { pelaksanaan pekerjaan. }\end{array}$ & 4,2 & 3 & 3,2 \\
\hline 3 & $\begin{array}{l}\text { Penyedia jasa menggunakan tenaga kerja ahli yang mampu } \\
\text { menerima konsep long segment }\end{array}$ & 3,75 & 3,06 & 3,2 \\
\hline 4 & $\begin{array}{l}\text { Penyedia jasa selalu berusah untuk mencapai standar kinerja } \\
\text { jalan yang telah disepakati. }\end{array}$ & 4,05 & 3 & 2,8 \\
\hline 5 & $\begin{array}{l}\text { Penyedia jasa melakukan investasi peralatan pemeliharaan } \\
\text { yang memadai }\end{array}$ & 4,1 & 2,8 & 2,93 \\
\hline 6 & $\begin{array}{l}\text { Penyedia jasa melakukan investasi personil dengan kualitas } \\
\text { baik untuk mencapai hasil kinerja yang maksimal. }\end{array}$ & 3,5 & 3,33 & 3,46 \\
\hline 7 & $\begin{array}{l}\text { Penyedia jasa menjadi manajer ruas jalan selama masa } \\
\text { kontrak. }\end{array}$ & 4,05 & 2,8 & 3 \\
\hline 8 & $\begin{array}{l}\text { Penyedia jasa harus membuat laporan mingguan dalam } \\
\text { pemenuhan tingkat layanan jalan dan laporan bulanan untuk } \\
\text { tingkat layanan jembatan. }\end{array}$ & 4,15 & 4,06 & 3,93 \\
\hline 9 & $\begin{array}{l}\text { Penyedia Jasa harus memenuhi semua indikator kinerja jalan } \\
\text { dan jembatan }\end{array}$ & 3,6 & 3,2 & 2,86 \\
\hline & Rata - rata & $\mathbf{3 , 8 9}$ & 3,15 & 3,11 \\
\hline
\end{tabular}

Lampiran 3. Hasil Analisis Mean terhadap Kesiapan Sistem Pengawasan menurut pihak pengguna jasa, kontraktor dan konsultan pengawas

\begin{tabular}{|c|c|c|c|c|}
\hline \multirow[b]{2}{*}{ No } & \multirow{2}{*}{$\begin{array}{l}\text { Pertanyaan } \\
\text { Indikator Sistem Pengawasan }\end{array}$} & Mean & Mean & Mean \\
\hline & & $\begin{array}{c}\text { Kesiapan } \\
\text { Pengguna Jasa }\end{array}$ & $\begin{array}{l}\text { Kesiapan } \\
\text { Kontraktor }\end{array}$ & $\begin{array}{l}\text { Kesiapan Konsultan } \\
\text { Pengawas }\end{array}$ \\
\hline 1 & $\begin{array}{l}\text { Pejabat Pembuat Komitmen (PPK) melakukan inspeksi lapangan } \\
\text { setiap saat. }\end{array}$ & 4,1 & 3,66 & 4,33 \\
\hline 2 & $\begin{array}{l}\text { Pengawasan dari direksi teknis (pihak proyek) dilakukan rutin } \\
\text { atau setiap hari. }\end{array}$ & 4 & 3 & 4,13 \\
\hline 3 & $\begin{array}{l}\text { Adanya sanksi atas tidak terpenuhinya indikator kinerja jalan dan } \\
\text { jembatan yang ada dalam kontrak. }\end{array}$ & 4,1 & 3,4 & 3,6 \\
\hline & Rata - rata & 4,06 & 3,35 & 4,02 \\
\hline
\end{tabular}


Lampiran 4. Hasil Analisis Mean terhadap Kesiapan Sistem Pembayaran menurut pihak pengguna jasa, kontraktor dan konsultan pengawas

\begin{tabular}{|c|c|c|c|c|}
\hline \multirow[b]{2}{*}{ No } & \multirow[b]{2}{*}{$\begin{array}{l}\text { Pertanyaan } \\
\text { Indikator Sistem Pembayaran }\end{array}$} & Mean & Mean & Mean \\
\hline & & $\begin{array}{c}\text { Kesiapan } \\
\text { Pengguna Jasa }\end{array}$ & $\begin{array}{l}\text { Kesiapan } \\
\text { Kontraktor }\end{array}$ & $\begin{array}{l}\text { Kesiapan Konsultan } \\
\text { Pengawas }\end{array}$ \\
\hline 1 & $\begin{array}{l}\text { Sistem pembayaran berdasarkan volume (volume based) yang } \\
\text { akan dikalikan dengan harga per satuan pekerjaan. }\end{array}$ & 4,05 & 4,06 & 4,06 \\
\hline 2 & Pembayaran prestasi pekerjaan dilakukan dengan cara bulanan & 4,05 & 4,06 & 4,33 \\
\hline 3 & $\begin{array}{l}\text { Tidak diberlakukan serah terima pekerjaan sebagian atau secara } \\
\text { parsial. }\end{array}$ & 3,9 & 3,13 & 3,2 \\
\hline 4 & $\begin{array}{l}\text { Pembayaran sertifikat bulanan (monthly certificate) selanjutnya } \\
\text { dapat dilakukan apabila penyedia jasa telah memenuhi kewajiban } \\
\text { pembayaran akibat keterlambatan pemenuhan tingkat layanan } \\
\text { jalan dan jembatan. }\end{array}$ & 3,95 & 2,8 & 3,66 \\
\hline 5 & $\begin{array}{l}\text { Apabila total nilai pemotongan pembayaran akibat keterlambatan } \\
\text { pemenuhan tingkat layanan jalan dan jembatan lebih besar } 5 \% \\
\text { dari nilai lingkup pekerjaan pemeliharaan jalan dan jembatan, } \\
\text { maka kontrak dinyatakan kritis. }\end{array}$ & 3,85 & 2,53 & 2,93 \\
\hline 6 & $\begin{array}{l}\text { Apabila pelaksanaan lingkup pekerjaan pemeliharaan rutin jalan } \\
\text { dan pemeliharaan rutin jembatan tidak atau belum dilaksanakan } \\
\text { sesuai dengan jadwal pelaksanaan pekerjaan yang telah disetujui } \\
\text { oleh PPK, maka pembayaran prestasi seluruh lingkup pekerjaan } \\
\text { akan ditunda sampai dengan pelaksanaan pemeliharaan rutin } \\
\text { jalan dan jembatan telah dilaksanakan sesuai jadwal pelaksanaan } \\
\text { dan hasilnya memenuhi tingkat layanan jalan dan jembatan. }\end{array}$ & 3,85 & 3,4 & 3,53 \\
\hline 7 & $\begin{array}{l}\text { jika PPK atau direksi teknis menemukan suatu bagian jalan atau } \\
\text { jembatan yang tidak memenuhi kriteria tingkat layanan, maka } \\
\text { hasil inspeksi akan disampaikan kepada penyedia jasa, dan jika } \\
\text { penyedia jasa tidak dapat menindaklanjuti untuk melakukan } \\
\text { perbaikan, maka akan dikenakan sanksi pemotongan } \\
\text { pembayaran. }\end{array}$ & 3,9 & 3,53 & 4,13 \\
\hline & Rata - rata & 3,93 & 3,36 & 3,69 \\
\hline
\end{tabular}

Lampiran 5. Hasil Analisis Mean terhadap Kesiapan Aspek Regulasi menurut pihak pengguna jasa, kontraktor dan konsultan pengawas

\begin{tabular}{|c|c|c|c|c|}
\hline \multirow[b]{2}{*}{ No } & \multirow{2}{*}{$\begin{array}{l}\text { Pertanyaan } \\
\text { Indikator Aspek Regulasi }\end{array}$} & Mean & Mean & Mean \\
\hline & & $\begin{array}{c}\text { Kesiapan } \\
\text { Pengguna Jasa }\end{array}$ & $\begin{array}{l}\text { Kesiapan } \\
\text { Kontraktor }\end{array}$ & $\begin{array}{l}\text { Kesiapan Konsultan } \\
\text { Pengawas }\end{array}$ \\
\hline 1 & $\begin{array}{l}\text { Adanya penyesuaian masa kontrak menjadi kontrak tahun } \\
\text { jamak. }\end{array}$ & 4,05 & 3,53 & 2,93 \\
\hline 2 & $\begin{array}{l}\text { Adanya peraturan yang mengatur prosedur kontrak long } \\
\text { segment. }\end{array}$ & 3,6 & 2,73 & 2,8 \\
\hline & Rata - rata & 3,82 & 3,13 & 2,86 \\
\hline
\end{tabular}

